Fourth International Conference on Sustainable Construction Materials and Technologies

http://www.claisse.info/Proceedings.htm

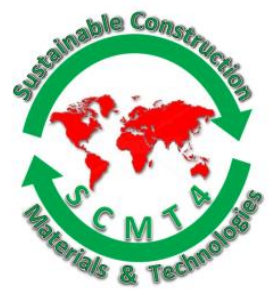

SCMT4

Las Vegas, USA, August 7-11, 2016

\title{
Study on Chloride Ion Penetration Model Considering Water Absorption in Concrete
}

\author{
Kentaro Koike $^{1 \mathrm{a}}$, Toshinobu Yamaguchi ${ }^{1 \mathrm{~b}}$, Koji Takewaka ${ }^{1 \mathrm{c}}$, Yoshikazu Akira ${ }^{1 \mathrm{~d}}$, and \\ Kohei Fukushige ${ }^{1 e}$
}

${ }^{1}$ Kagoshima University - 1-21-40, Korimoto, Kagoshima-City, Kagoshima-Prefecture, 890-0065, Japan.

${ }^{1 a}$ Email: <k2079773@kadai.jp>, ${ }^{1 b}$ Email: <yamaguch@oce.kagoshima-u.ac.jp>,

${ }^{1 c}$ Email: <takewaka@oce.kagoshima-u.ac.jp>, ${ }^{1 d}$ Email: < akira@oce.kagoshima-u.ac.jp>,

${ }^{l e}$ Email: <k9715337@kadai.jp>.

\begin{abstract}
The aim of the study is to experimentally clarify effects of water to cement ratio and cement types on chloride ion penetration with water absorption in concrete, and to verify applicability of chloride ion penetration model considering water absorption in concrete. From the experimental result, it is found that capillary water velocity and chloride ion diffusion coefficient correlate highly with continuity pore volume due to effect of water to cement ratio and cement types. And verification result of advection-diffusion model of chloride ion based on experimental result, it is confirmed that this model could evaluate characteristics of chloride ion penetration with water absorption.
\end{abstract}

\section{INTRODUCTION}

Recently, Fick's second law is widely used as one of the durability assessment methods of chloride attack in concrete structures due to its simplicity and applicability as a model to estimate the diffusion coefficient of chloride ion. But in actual environment, adsorption, immobilization and advection of chloride ion due to the capillary water movement due to wet-dry cycles is also broadly regarded as diffusion of chloride ion [Hamada et al. 1996]. Most of the marine structures located in tidal zone or splash zone undergo repeated wet-dry cycles. So, inclusion of water movement to concentration diffusion is not preferable. In the current durability assessment method, apparent diffusion coefficient are changed due to factors like water movement and chloride penetration under different environmental conditions even if materials used in RC structures are same. Recently, it is also reported that, in case of concrete highly resistive to chloride penetration, diffusion of chloride stagnates due to restricted water movement which is a solvent for chloride diffusion [Takahashi et al. 2010]. Hence this phenomenon cannot be explained by concentration diffusion model. In such case, application of current diffusion model, possibly reduce accuracy of predictions by water movement. However, there are a few case studies about relationship between water movement in capillary pore and chloride ion movement, mechanism of chloride penetration in actual phenomena is not clear. 
For these problems, we experimentally investigate characteristic of chloride ion penetration due to effect of water absorption and wet-dry cycles, and we construct chloride ion penetration model considering water movement. Especially, this paper is reported experimental result about effects of water to cement ratio and cement types on chloride ion penetration with water absorption, and verification result of chloride ion penetration model considering water absorption in concrete.

\section{EXPERIMENTAL OVERVIEW}

\section{Specimens}

Table 1 shows the mix proportions of mortars. The mixture were 5 types, OPC40, OPC50 and OPC60 based on ordinary Portland cement (here-in-after called OPC), these were changed water to cement ratio at $0.4,0.5$ and 0.6. Also, based on OPC50, BB50 replacing part of OPC by blast furnace slag (anhydrite is added to improve early-age strength of BB50.), FB50 replacing part of OPC by fly ash. In all the cases, paste volume of mortar is adjusted to satisfy the target mortar flow value, $150 \pm 10 \mathrm{~mm}$.

Prismatic specimens of $4 \mathrm{~cm} \times 4 \mathrm{~cm} \times 12 \mathrm{~cm}$ are prepared and normal water cured for 28 days. And after curing, specimens were dried for 1 day under $20^{\circ} \mathrm{C}$ and $\mathrm{RH}=60 \%$. After dried, specimens surface except absorption face were covered by epoxy resin and aluminum tape. After sealing, initial water content in specimens were adjusted to use chloride ion penetration test. In this study, "pseudo saturated condition" and "absolute dry condition" were considered as initial water content. Here, "pseudo saturated condition" means just about nearly saturated condition. That is, dry region is remaining a little in specimens, but water movement does not occur. Also, pseudo saturated condition was achieved by immersion of specimens under the distilled water when weight difference from previous day is less than $0.1 \%$. And absolute dry condition of specimens was achieved by drying oven at $105^{\circ} \mathrm{C}$ when weight difference from previous day is less than $0.1 \%$.

Table 1. Mix proportion of mortar

\begin{tabular}{|c|c|c|c|c|c|c|c|c|}
\hline & \multirow[t]{2}{*}{$W / B$} & \multirow[t]{2}{*}{ Paste volume ratio } & \multicolumn{6}{|c|}{ Unit Weight $\left(\mathrm{kg} / \mathrm{m}^{3}\right)$} \\
\hline & & & $W$ & $C$ & $B F S$ & $F$ & Anhydrite & $S$ \\
\hline OPC40 & 0.4 & 0.470 & 262 & 656 & - & - & - & 1399 \\
\hline OPC50 & 0.5 & 0.415 & 254 & 508 & - & - & - & 1544 \\
\hline BB50 & & 0.420 & 256 & 256 & 251 & - & 5.11 & 1518 \\
\hline FB50 & & 0.425 & 252 & 404 & - & 101 & - & 1518 \\
\hline OPC60 & 0.6 & 0.385 & 252 & 420 & - & - & - & 1624 \\
\hline
\end{tabular}

\section{Method of chloride ion penetration}

Figure 1 shows the method of chloride ion penetration test. Here, absorption face of the specimen is completely soaked in $10 \% \mathrm{NaCl}$ solution. However, opposite face of the specimen can be exposed to atmosphere. After the beginning of test, the specimens are cut to obtain 12 slices of $1 \mathrm{~cm}$ each from absorption face to measure saturation ratio profile and total chloride ion profile in each predefined absorption days $(0,1,3,7,14,28,56,91,182,365$ days) for which the specimens are subjected.

Then, according to Equation (1) to Equation (3), saturation ratio is calculated by dividing "water content of test pieces at each absorption days" by "water content of test pieces in saturated condition". Here, saturation treatment of test pieces used by vacuum desiccator, absolute dry treatment of test pieces used by drying oven at $105^{\circ} \mathrm{C}$. Also, total chloride ion profile in the specimens is measured in accordance with JCI-SC4 (Japan Concrete Institute standard). 


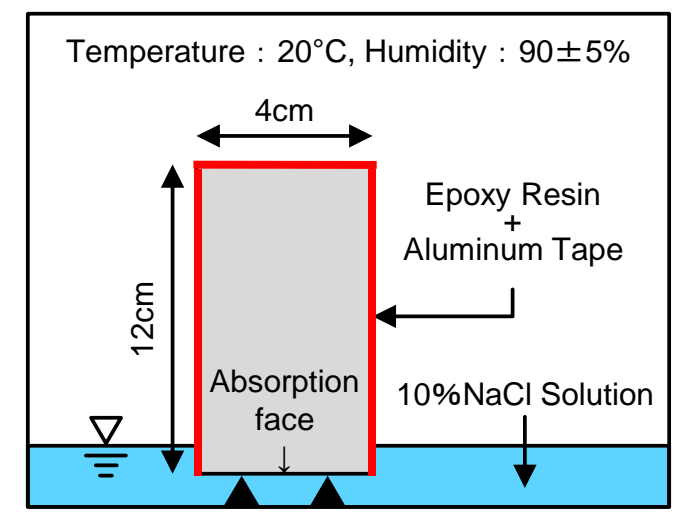

Figure 1. Chloride ion penetration test setup

$$
\begin{aligned}
& \left(W_{t}-W_{d r y}\right) / W_{d r y} \times 100=\theta_{t} \\
& \left(W_{s a t}-W_{d r y}\right) / W_{d r y} \times 100=\theta_{s a t} \\
& \theta_{t} / \theta_{s a t} \times 100=S r
\end{aligned}
$$

Where, $W_{t}$ : Weight of test piece at $\mathrm{t}$ days $(\mathrm{g}), W_{d r y}$ : Weight of test piece in absolute dry condition $(\mathrm{g})$, $W_{\text {sat }}$ : Weight of test piece in saturated condition $(\mathrm{g}), \theta_{t}$ : Water content of test piece at $\mathrm{t}$ days $(\%), \theta_{\text {sat }}$ : Water content of test piece in saturated condition (\%), $\mathrm{Sr}$ : Saturation ratio(\%).

In addition, mercury intrusion porosimetry test was carried out by using specimens just before start of chloride ion penetration test to clarify difference of pore structure due to effect of water to cement ratio and cement types.

\section{RESULTS OF CHLORIDE ION PENETRATION TEST}

\section{Experiment on mortar under pseudo saturated condition}

\section{(1) Saturation ratio profile}

Figure 2 shows time-dependent change of saturation ratio profile when the specimens are subjected to chloride ion penetration test under pseudo saturated condition $(0,1,7,28,91,365$ days). In any of these cases, in spite of absorption time, the saturation ratio profile kept almost $90 \%$. So, it was assumed that water movement did not occur.

\section{(2) Total chloride ion profile}

Figure 3 shows time-dependent change of total chloride ion profile when the specimens are subjected to chloride ion penetration test under pseudo saturated condition $(0,1,7,28,91,365$ days). In any of these cases, the total chloride ion profile is corresponded to diffusion theory. That is, it is confirmed that chloride ion penetration was dominated by effect of diffusion under little water movement like pseudo saturated condition. Also, it was confirmed that the chloride ion penetration was inhibited with decrease of water to cement ratio and using blended cement.

Figure 4 shows time-dependent change of apparent diffusion coefficient of chloride ion calculated by fitting the total chloride ion profile to Fick's diffusion equation. Also, Equation (4) represent timedependent equation of apparent diffusion coefficient of chloride ion calculated by least-square method. In any of these cases, apparent diffusion coefficient reduced rapidly from beginning of test, and this coefficient converged to steady value with time passage. 


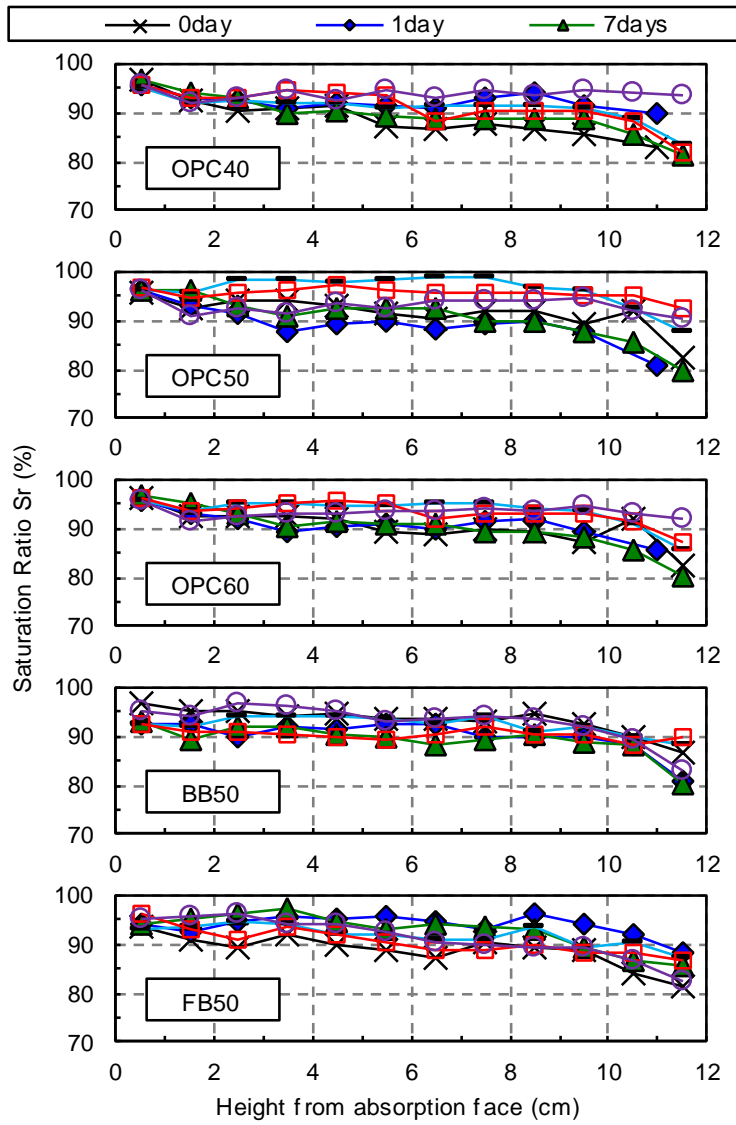

Figure 2. Saturation ratio profile (Pseudo saturation condition mortar)
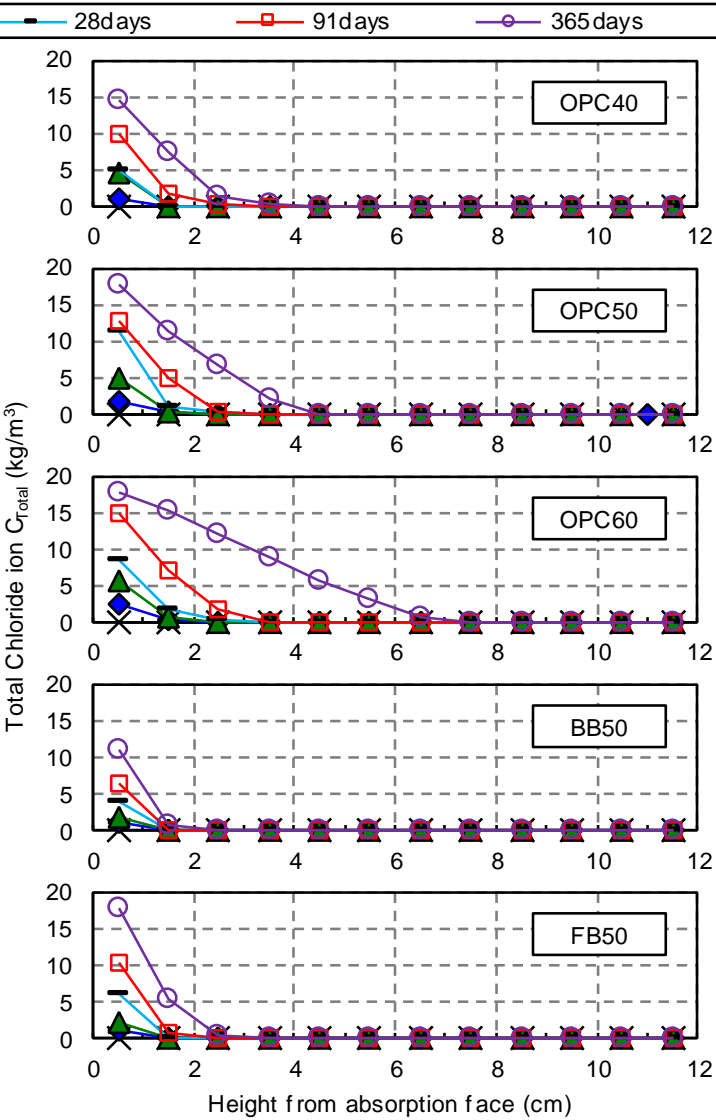

Figure 3. Total chloride ion profile (Pseudo saturation condition mortar)

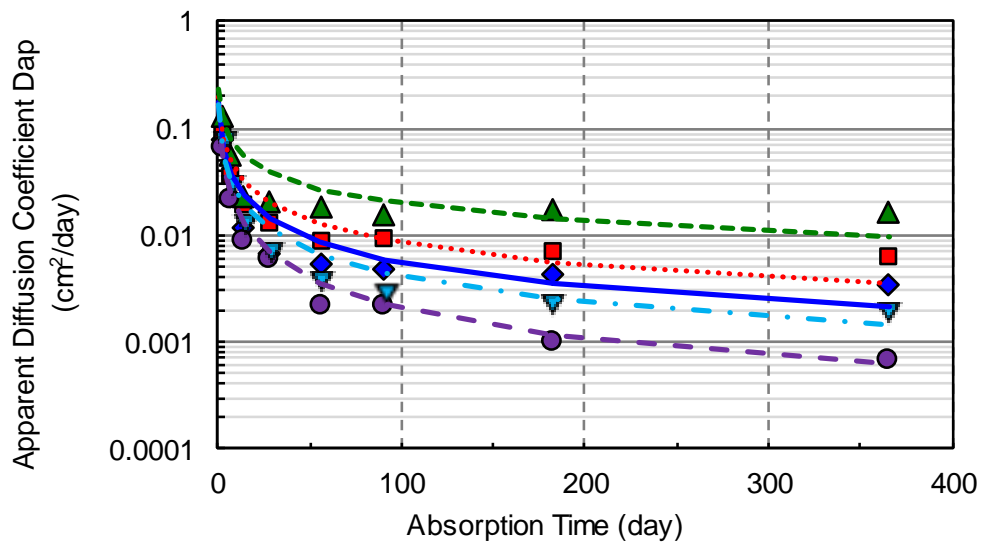

\begin{tabular}{|c|c|c|}
\hline Mesured & \multicolumn{2}{|c|}{ Approximation } \\
\hline - OPC40 & \multicolumn{2}{|c|}{$\longrightarrow$ OPC40 } \\
\hline - OPC50 & \multicolumn{2}{|c|}{......... OPC50 } \\
\hline$\triangle$ OPC60 & \multicolumn{2}{|c|}{---- OPC60 } \\
\hline - BB50 & \multicolumn{2}{|c|}{--- BB50 } \\
\hline$\nabla$ FB50 & \multicolumn{2}{|c|}{$-\cdots$ FB50 } \\
\hline \multicolumn{3}{|c|}{ Experimental Factor } \\
\hline & $a$ & $b$ \\
\hline OPC40 & 0.181 & 0.756 \\
\hline OPC50 & 0.196 & 0.684 \\
\hline OPC60 & 0.235 & 0.539 \\
\hline BB50 & 0.167 & 0.951 \\
\hline FB50 & 0.170 & 0.808 \\
\hline
\end{tabular}

Figure 4. Apparent diffusion coefficient (Pseudo saturation condition mortar)

$$
D_{a p}=a(t+1)^{-b}
$$

Where,

$D_{a p}:$ Apparent diffusion coefficient ( $\mathrm{cm}^{2} /$ day $), a, b \quad$ : Experimental factor, $t$ : Absorption time (day). 


\section{EXPERIMENT ON MORTAR UNDER ABSOLUTE DRY CONDITION}

\section{(1) Saturation ratio profile}

Figure 5 shows time-dependent change of water content when the specimens are subjected to chloride ion penetration test under absolute dry condition $(0,1,7,28,91,365$ days). Initially, it was assumed that saturation ratio increased kept $100 \%$ from absorption face to internal of specimens as characteristic of water movement. However, from experimental result, characteristic of water movement confirmed that saturation ratio changes linearly with gradient, and saturation ratio reduced rapidly from end point of linear part. It was assumed that water movement was inhibited due to pore-air pressure caused by trapped air in the specimens. In addition, from previous study [Akita et al. 1990], it was suggested that characteristic of water movement were rectilinear capillary water movement at highly water content region, and water vapor diffusion from end point of capillary water at middle and lower water content region. And so, saturation ratio profile of Figure 5 was evaluated according to the following assumption; linear section is capillary water movement, diffusely profile is water vapor diffusion. From this assumption, focused on effect of water to cement ratio, effect capillary water movement became pronounced with increasing of water to cement ratio was assumed. Also, in the case of OPC40, capillary water movement stagnated at 28 days at $5.5 \mathrm{~cm}$ height, water vapor diffusion is dominant at over $5.5 \mathrm{~cm}$ height. On the other hand, in cases of OPC50 at 91days and OPC60 at 28days, capillary water movement reached at opposite face. Especially, in the case of OPC60, saturation ratio was more increased from 28days, and saturation ratio profile became homogeneous at 91days. Also, focused on effect of cement types, BB50 and FB50 inhibited water movement clearly compared to OPC50 in spite of same water to cement ratio. Especially, in the case of BB50, capillary water movement reached at only $2 \sim 3 \mathrm{~cm}$ height.

\section{(2) Total chloride ion profile}

Figure 6 shows time-dependent change of total chloride ion when specimens are subjected to chloride ion penetration test under absolute dry condition $(0,1,7,28,91,365$ days). In any of these cases, characteristic of total chloride ion penetration in water absorption was greatly different compared to result of using pseudo saturated condition mortar. Noteworthy point is that chloride ion penetrates rapidly from just after the beginning of test. In addition, saturation ratio profile and total chloride ion profile just about corresponded each other, so that chloride ion penetrates with water movement. That is, chloride ion penetration became pronounced with increasing water to cement ratio as is the case with saturation ratio profile, and BB50 and FB50 inhibited chloride ion penetration greatly.

However, from comparison in more detail of both profiles, different characteristics in each other were confirmed. First, focused on around the absorption face, chloride ion content was increased with time passage in spite of constant value at saturation ratio profile. On the other hand, focused on OPC40, BB50 and FB50 at 365days, it was confirmed that maximum height of water movement and that of chloride ion penetration did not correspond in each other. That is, chloride ion did not penetrated in spite of water existing by water movement.

Therefore, reasons of these phenomenon is assumed as follows;

- Increment phenomenon of chloride ion around absorption face was assumed effect of immobilization and adsorption to chloride ion [Maruya et al. 1998].

- Also, difference between water movement height and chloride ion penetration height confirmed at diffusely profile in the saturation ratio profile. As assumed at the beginning of this section 3.2 (1), diffusely profile is water vapor diffusion, and chloride ion could not penetrate with water vapor diffusion. Therefore, this phenomenon is explainable as effect of water vapor diffusion. 


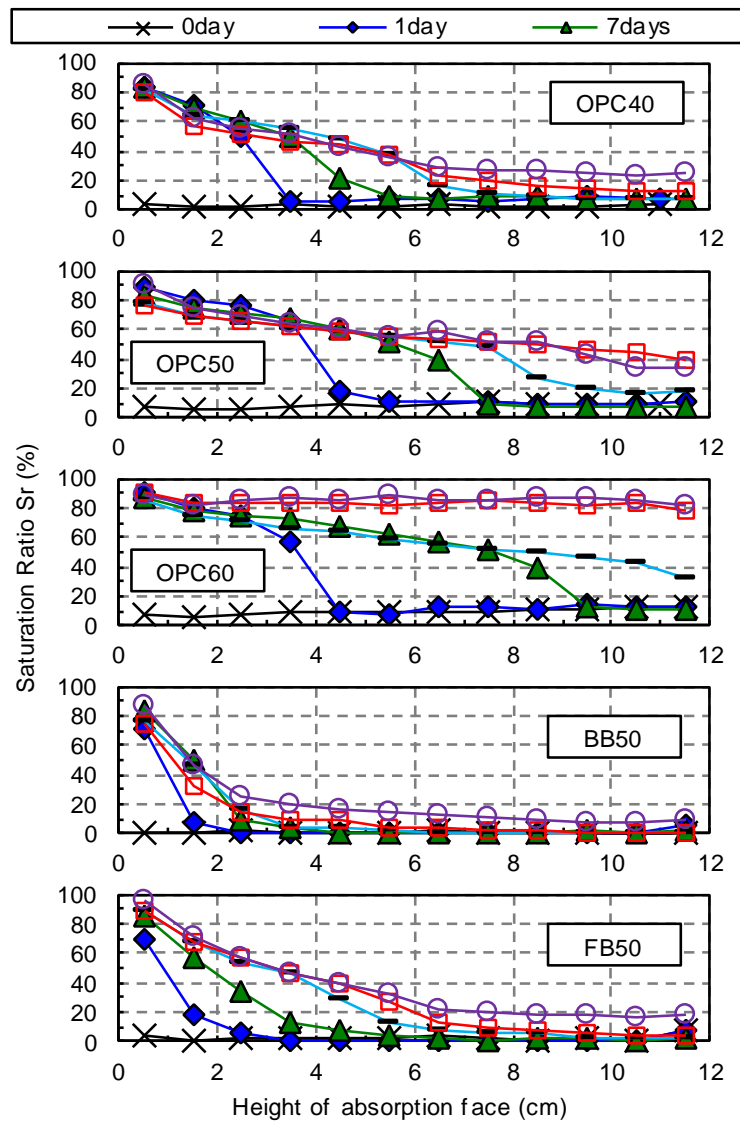

Figure 5. Saturation ratio profile (Absolute dry condition mortar)
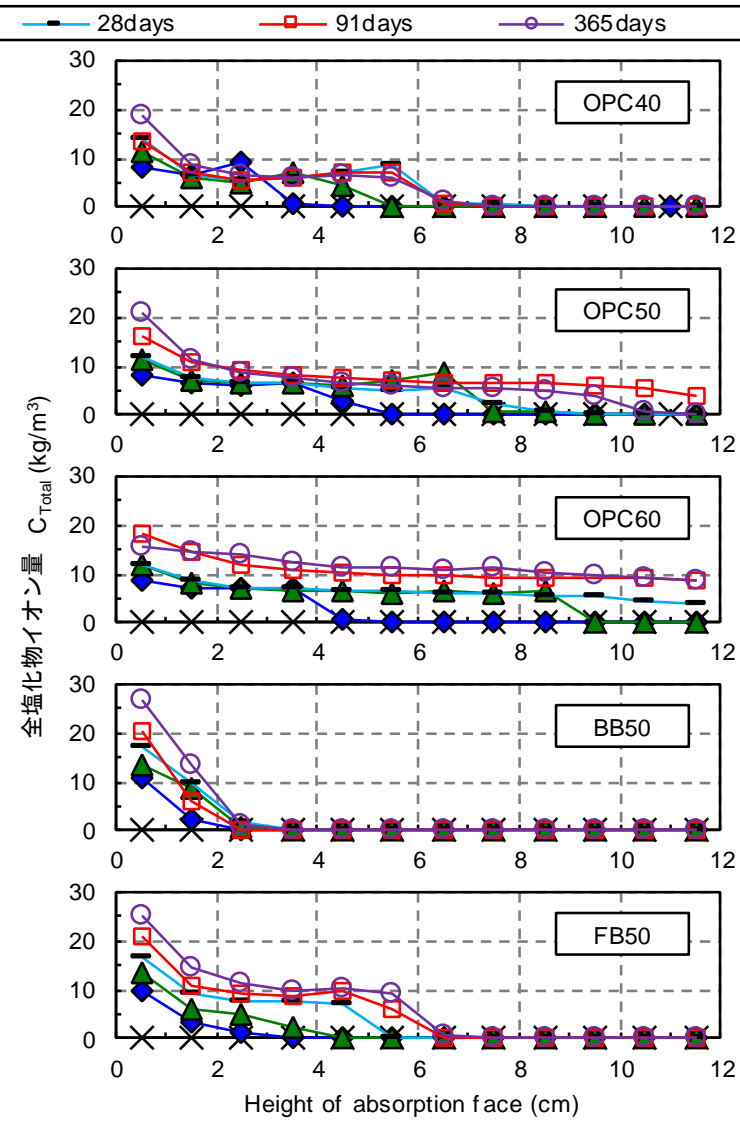

Figure 6. Total chloride ion profile (Pseudo saturation condition mortar)

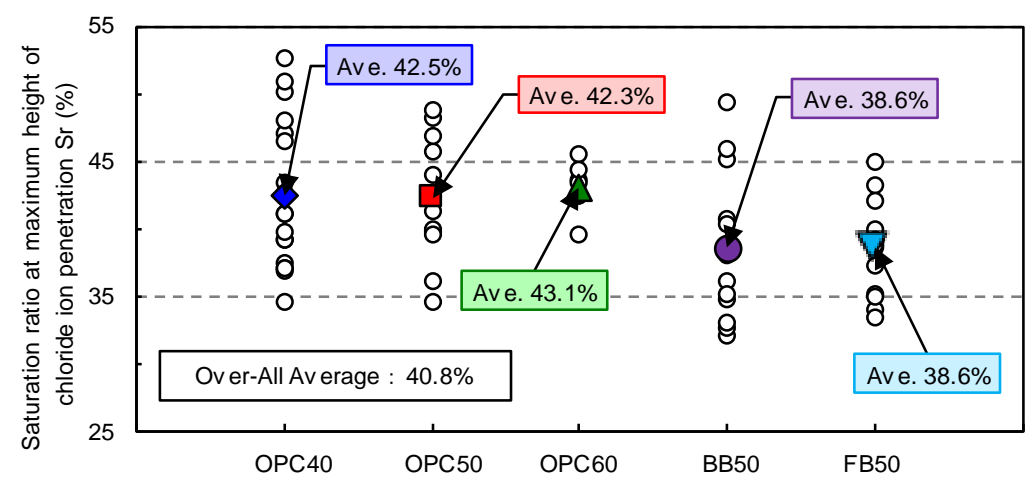

Figure 7. Saturation ratio at maximum height of chloride ion penetration

Also, from characteristic that chloride ion only penetrate in the capillary water, correlation between maximum height of chloride ion penetration each days and saturation ratio at same height with chloride ion penetration were evaluated by Figure 5 and Figure 6 to clarify limit saturation ratio of chloride ion penetration. Figure 7 shows saturation ratio at maximum height of chloride ion penetration. There were some variance by test period, water to cement ratio and cement types, saturation ratio at maximum height of chloride ion penetration was almost $40 \%$. That is to say, capillary water movement is dominant process at saturation ratio $40 \sim 100 \%$, and water vapor diffusion is dominant process at less than $40 \%$. 


\section{CHLORIDE ION PENETRATION MODEL CONSIDERING WATER ABSORPTION}

\section{Governing equation}

From experimental result in section 3.2, it was confirmed as characteristic of chloride ion penetration with water movement that chloride ion penetrates not only effect of concentration diffusion but also effect of advection of capillary water. Therefore, chloride ion penetration model considering water movement was defined as follow equation (5) and equation (6) as advection-diffusion equation [Maruya et al. 1998] [Md. Shafiqul ISLAM et al. 2011]. Especially, advection term was defined as proportional absorbed water and chloride ion content different with other terms.

And, verification of applicability of this penetration model was carried out by differential analysis of chloride ion penetration test by using absolute dry condition mortar.

$$
\begin{aligned}
& \frac{d C}{d t}=D_{a p} \cdot \frac{d^{2} C}{d x^{2}}-v_{w} \cdot \frac{d S r}{d x} \cdot C^{\prime} \\
& C^{\prime}=\frac{1}{100} \times \frac{\theta_{s a t}}{100} \times \frac{C_{N a C l}}{100} \times \frac{35.5}{58.5} \times \gamma_{S P}
\end{aligned}
$$

Where, $C$ : Chloride ion content $\left(\mathrm{kg} / \mathrm{m}^{3}\right), S r$ : Saturation ratio (\%), $D_{a p}$ : Apparent diffusion coefficient $\left(\mathrm{cm}^{2} /\right.$ day), $v_{w}$ : Capillary water velocity (cm/day), $t$ : Absorption time (day), $x$ : Height from absorption face $(\mathrm{cm}), C^{\prime}$ : Conversion factor of saturation ratio to chloride ion content $\left(\left(\mathrm{kg} / \mathrm{m}^{3}\right) / \%\right), \theta_{\text {sat }}$ : Water content in saturated condition (\%), $C_{\mathrm{NaCl}}$ : Concentration of $\mathrm{NaCl}$ solution $(\%), \gamma_{S P}$ : Unit volume weight of specimen in absolute dry condition $\left(\mathrm{kg} / \mathrm{m}^{3}\right)$.

\section{Analytical parameter}

Analytical parameter (apparent diffusion coefficient, capillary water velocity, surface chloride ion content) were determined as follows.

First, based on result of using pseudo saturated condition mortar, apparent diffusion coefficient evaluated with relationship of pore structure. Figure 8 shows pore diameter profile. From this figure, mercury emission volume after extrusion phase was regarded as continuity pore volume [Koike et al. 2015]. In addition, pore structure factor was defined as continuity pore volume-tortuosity factor relation equation (7). Also, tortuosity factor determined based on previous study [Sugiyama et al. 2004] [Sasaki et al. 2007]. Figure 9, equation (8) and equation (9) shows relationship between pore structure factor and experimental factors " $a$ " and " $b$ " in equation (4).

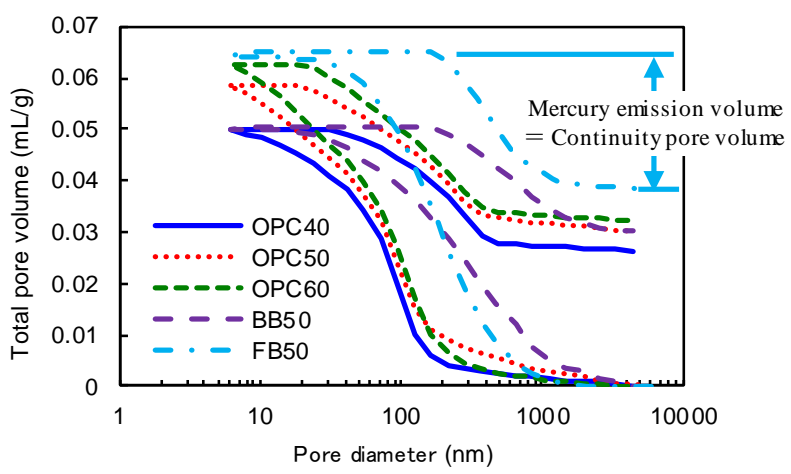

\begin{tabular}{|c|c|c|}
\hline \multicolumn{3}{|c|}{ Pore Structure } \\
\hline & $V_{c n t}$ & $\tau^{*}$ \\
\hline OPC40 & 0.021 & 4.6 \\
\hline OPC50 & 0.024 & 4.6 \\
\hline OPC60 & 0.026 & 4.6 \\
\hline BB50 & 0.028 & 8.0 \\
\hline FB50 & 0.031 & 6.5 \\
\hline ※ Reference value \\
from previous study
\end{tabular}

Figure 8. Comparison of pore diameter profile 


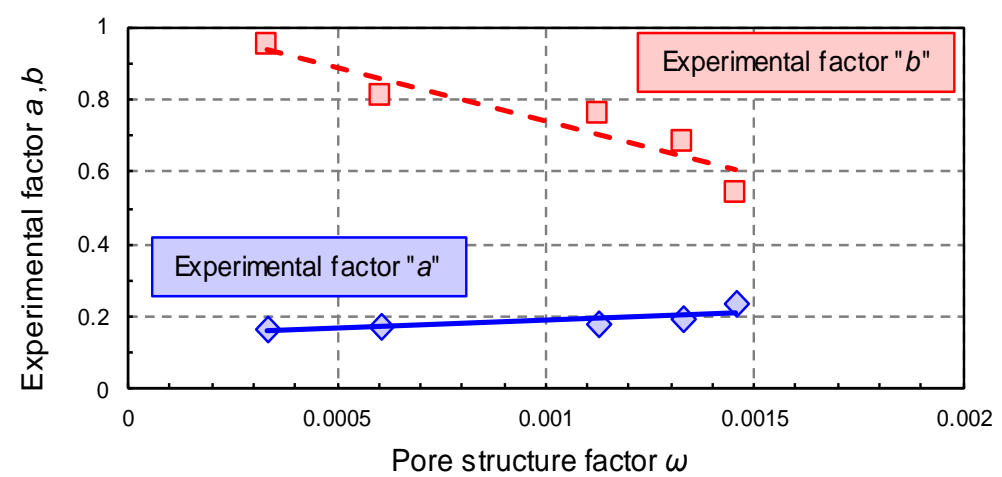

Figure 9. Relationship between pore structure factor and experimental factors

$$
\begin{aligned}
& \omega=V_{\text {cnt }} / \tau^{2} \\
& a=48.08 \omega+0.14 \\
& b=-296.13 \omega+1.03
\end{aligned}
$$

Where, $\omega$ : Pore structure factor, $V_{c n t}$ : Continuity pore volume $(\mathrm{mL} / \mathrm{g}), \tau:$ Tortuosity factor, $a, \quad b \quad$ : Experimental factor.

Second, capillary water velocity evaluated with relationship of pore structure. From result of saturation ratio profile by using absolute dry condition mortar, height of saturation ratio $40 \%$ was regarded as height of capillary water movement in figure 5. Figure 10 and equation (10) shows time-dependent change of height of capillary water movement. In any of these cases, capillary water moved rapidly from beginning of test, and stagnated with time passage. In addition, Figure 11, equation (11) and equation (12) shows relationship between pore structure factor and experimental factors " $\alpha$ " and " $\beta$ " in equation (10). And, capillary water velocity was obtained by differentiating equation (10) with respect to time. (Equation 13)

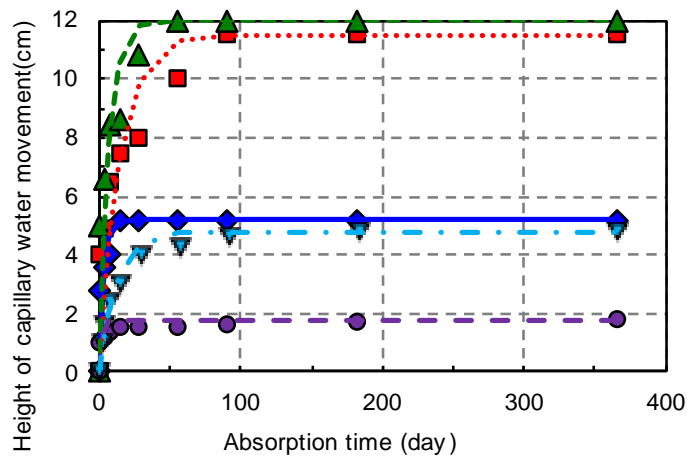

Figure 10. Time-dependent change of height of capillary water movement

$$
\begin{aligned}
& X_{\text {cap }}=\alpha[1-\exp (-\beta \cdot t)] \\
& \alpha=8.5 \times 10^{3} \cdot \omega-1.2 \\
& \beta=-2.6 \times 10^{2} \cdot \omega-0.5 \\
& v_{w}=\alpha \beta \cdot \exp (-\beta \cdot t)
\end{aligned}
$$

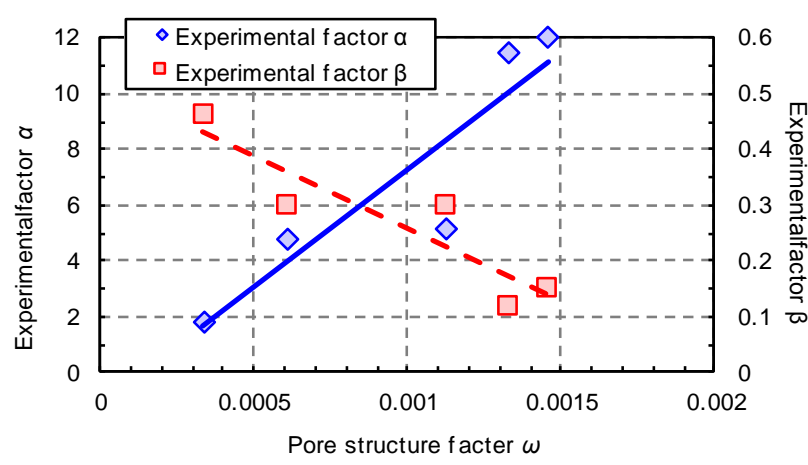

Figure 11. Relationship between pore structure factor and experimental factors

Where, $X_{\text {cap }}$ : Height of capillary water movement $(\mathrm{cm}), v_{w}$ : Capillary water velocity $(\mathrm{cm} /$ day $), t$ : Absorption time (day), $\omega$ : Pore structure factor, $\alpha, \beta$ : Experimental factor. 
Finally, determination of surface chloride ion content. From result of total chloride ion profile by using absolute dry condition mortar, figure 12 shows time-dependent change of surface chloride ion content. Surface chloride ion content increased from beginning of test, and converged to steady value with time passage. From this tendency, surface chloride ion content was formulated as follow equation (14).

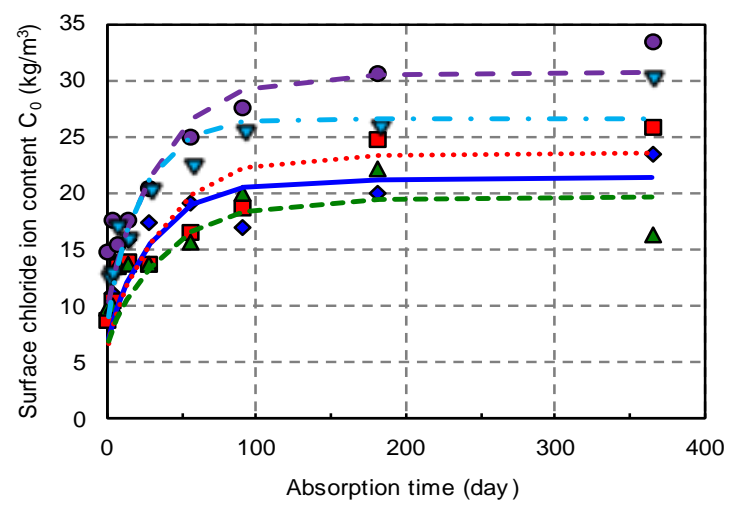

\begin{tabular}{|c|c|c|c|}
\hline \multicolumn{2}{|c|}{ Mesured } & \multicolumn{2}{|c|}{ Approximation } \\
\hline \multirow{2}{*}{\multicolumn{2}{|c|}{$\begin{array}{l}\text { - OPC40 } \\
\text { - OPC50 }\end{array}$}} & \multicolumn{2}{|c|}{$\longrightarrow$ OPC40 } \\
\hline & & \multirow{4}{*}{\multicolumn{2}{|c|}{$\begin{array}{l}\cdots . . \cdots \cdot \text { OPC50 } \\
-\cdots--- \text { OPC60 } \\
--- \text { BB50 } \\
-\cdots-\text { FB50 }\end{array}$}} \\
\hline$\triangle \mathrm{OPC}$ & & & \\
\hline - BB50 & & & \\
\hline$\nabla$ FB50 & & & \\
\hline \multicolumn{4}{|c|}{ Experimental Factor } \\
\hline & $\mathrm{C}_{\text {oini }}$ & $F$ & $G$ \\
\hline OPC40 & 9.98 & 0.053 & 10.06 \\
\hline OPC50 & 16.68 & 0.011 & 9.59 \\
\hline OPC60 & 9.12 & 0.025 & 10.21 \\
\hline BB50 & 19.50 & 0.018 & 12.73 \\
\hline FB50 & 16.46 & 0.025 & 11.48 \\
\hline
\end{tabular}

Figure 12. Time-dependent change of surface chloride ion content

$$
C_{0}=C_{0 i n i}+F[1-\exp (-G t)]
$$

Where, $C_{0}$ : Surface chloride ion content $\left(\mathrm{kg} / \mathrm{m}^{3}\right), C_{\text {oini }}$ : Converted value of concentration of $\mathrm{NaCl}$ solution to surface chloride ion content $\left(\mathrm{kg} / \mathrm{m}^{3}\right), t$ : Absorption time (day), $F, G$ : Experimental factor.

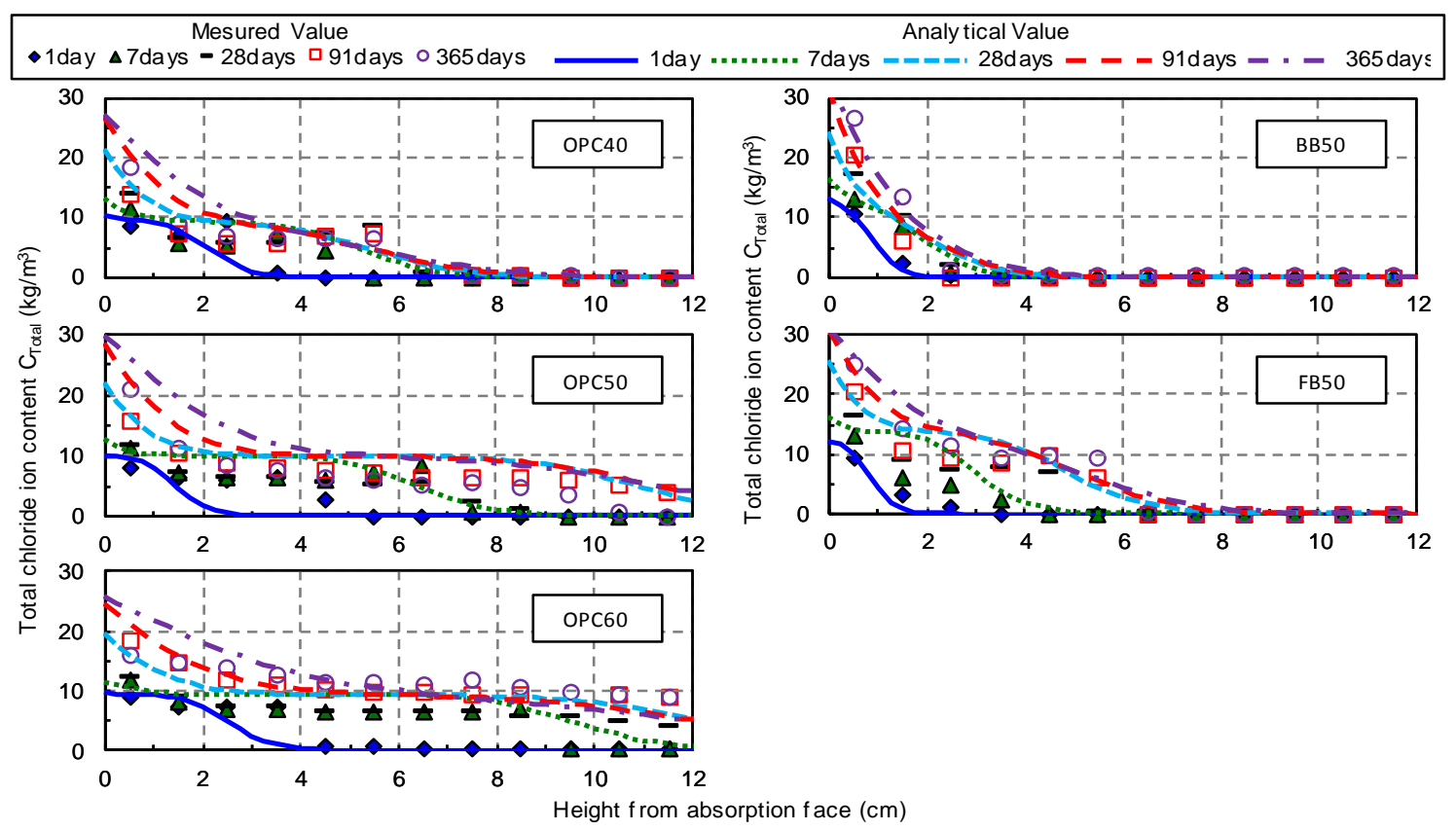

Figure 13. Analytical result of total chloride ion content

\section{Comparison of total chloride ion content between measured value and analytical value}

Figure 13 shows comparison of total chloride ion content between measured value and analytical value. In any of these cases, according to chloride ion penetration with capillary water movement, total chloride ion profile was mostly similar in trend between measured value and analytical value. Also, increment phenomenon of chloride ion around absorption face could be reproduced. In addition, it was also 
reproduced that effect of water to cement ratio and cement types defined from effect of pore structure. Hence, it is suggested that advection-diffusion model is applicable as chloride ion penetration model considering water movement.

\section{CONCLUSION}

- In case of experiment on mortar under pseudo saturated condition, water movement was not observed, and the chloride ion penetrates according to diffusion process. In addition, apparent diffusion coefficient had strong relationship with pore structure (continuity pore volume and tortuosity factor).

- In case of experiment on mortar under absolute dry condition, chloride ion penetrated rapidly with water movement. In addition, focused on around the absorption face, chloride ion content was increased with time passage due to effect of immobilization and adsorption to chloride ion. Also, it was confirmed that capillary water movement is dominant process at saturation ratio $40 \sim 100 \%$, and water vapor diffusion is dominant process at less than $40 \%$.

- Based on experimental investigation, advection-diffusion model is suggested as chloride ion penetration model considering water movement. Result of verification of this model, total chloride ion profile was mostly similar in trend between measured value and analytical value. Also, increment phenomenon of chloride ion around absorption face could be reproduced. In addition, it was also reproduced that effect of water to cement ratio and cement types defined from effect of pore structure.

\section{REFERENCES}

Akita, H., Fujiwara, T., Ozaka, Y. (1990). "Water Movement within Mortar Due to Drying and Wetting." Journal of JSCE, 1990(420), 61-69.

Hamada, H., Swamy, R.N. (1996). "A Discussion on the Process and the Amount of Chloride Intrusion into Concrete in Various Marine Environment.", Concrete Research and Technology, 7(1), 11-22.

Koike, K., Yamaguchi, T., Takewaka, K., Akira, Y., Fukushige, K. (2015). "STUDY ON EFFECT OF PORE STRUCTURE ON PENETRATION PROPERTY OF CHLORIDE ION IN CONCRETE.", The Fifth International Conference on Construction Materials, 178, 9 pages.

Maruya, T., TANGTERMSIRIKUL, S., Matsuoka, Y. (1998). "MODELING OF CHLORIDE ION MOVEMENT AT THE SURFACE LAYER OF HARDEND CONCRETE.", Journal of JSCE, 1998(585), 79-95.

Md. Shafiqul ISLAM (2011). "Stagnation of Liquid Water/ Chloride Ion Penetration in Concrete and Application of the Knowledge to Durability Design and LCCA", Doctoral thesis at University of Tokyo.

Sasaki, K., Yokosawa, R., Saeki, T. (2007). "Influence of carbonation on chloride ions diffusivity in cementitious materials." Proceedings of the Japan Concrete Institute, 29(1), 1035-1040.

Sugiyama, T., Shimizu, S., Ritthichauy, W., Tsuji, Y. (2004). "DETERMINATION OF PORE STRUCTURE CHARACTERISTIC OF MORTAR USING A STEADY-STATE MIGRATION TEST.” Journal of JSCE, 2004(767), 227-238.

Takahashi, Y., Inoue, S., Akiyama, H., Kishi, T. (2010). "CHLORIDE ION PENETRATION BEHAVIOR OF FLY ASH CONCRETE FOCUSED ON INFLUENCE OF SURVEYED AGE." Proceedings of the Japan Concrete Institute, 36(1), 904-909. 